\title{
Apuntes para una historia \\ DE LAS REPRESENTACIONES DE UNA NATURALEZA y cuerpos abyectos: Virreinato del Perú, SIGLO XVI
}

\author{
Elizabeth Mejías Navarrete \\ Universidad de Chile \\ elizabbetha@gmail.com
}

\section{Resumen}

Este artículo analiza los discursos y representaciones desplegadas en torno a las enfermedades atribuidas a los indígenas circunscritos al Virreinato del Perú para el período 1570-1600 en las Relaciones Geográficas de Indias y algunos tratados médicos relevantes de la época. Considerando el contexto de dominación colonial en que estas descripciones fueron elaboradas, es factible señalar que expresan algo más que una preocupación "científico-médica" o sanitaria, en la medida en que aludirían a un conjunto de ideas relacionadas con visiones sobre el ordenamiento simbólico, político y moral del espacio y los sujetos coloniales.

Palabras clave: sujetos coloniales, espacio, cuerpo, discurso, representación, colonización, Relaciones Geográficas.

\section{Abstract}

This article analyzes the discourses and representations deployed around the diseases attributed to the indigenous confined to the Viceroyalty of Peru for the period 1570 - 1600 in the Geographical Relations of the Indies, and some contemporaries relevants medicals treaties. Considering the context of colonial domination in which these descriptions were developed it is feasible to express that there is more than a "scientific-medical" or health concern because they refer to a set of ideas related to views on the symbolic, political and moral order of the space and colonial subjects.

Key words: Colonial subject, space, body, speech, representation, colonization, Geographics Relations 
El descubrimiento, conquista y colonización del Nuevo Mundo dio lugar a masivas migraciones, destrucción de pueblos, mestizaje, apertura de nuevas rutas comerciales y formación del primer gran imperio europeo de ultramar. Ello se articuló sobre la base del legado del universalismo trasmitido desde la Antigüedad y la Edad Media, el cual establecía un derecho de dominio sobre la totalidad del mundo (Pagden, Señores 11-12). Desde ahí se erigió una relación de dominación en la que el conquistador se asume y construye como el dominador, mientras que el sujeto que se construye como indígena se representa como aquel que se debe subordinar ${ }^{2}$. Ello operó por medio de dos mecanismos: el uso de la violencia explícita (manifestada en la tortura, golpes, violaciones, castraciones, regímenes de trabajo, etc.) y la colonización del imaginario (Gruzinski). En mi propuesta de trabajo, la atención se centra en el segundo aspecto señalado, pues dar cuenta de la lógica de la dominación, supone poner al descubierto sus mecanismos no sólo en el plano de lo manifiesto, sino teniendo en cuenta los conceptos, representaciones, imaginarios y simbolismos que allí operan (Bourdieu; Maffesoli).

En el seno de la dominación española se desplegaron múltiples ejes que definieron la jerarquización de los sujetos: la noción de naturaleza, la

1 Los temas y documentos desarrollados aquí forman parte del proyecto Fondecyt núm. 1070938: Descripción geográfica y programa imperial, tensiones en las representaciones hispanas del territorio del Virreinato del Perú (1570-1601), cuya investigadora responsable es la profesora Alejandra Vega Palma. Además, este trabajo se nutrió y fue evaluado en el Seminario Troncal I: "Problemas fundamentales de la cultura latinoamericana. Construyendo identidades y diferencias: América entre dos rupturas (siglos XVI-XVIII)", perteneciente al programa de Magíster en Estudios Culturales Latinoamericanos de la Universidad de Chile. Profesores coordinadores: Alejandra Vega, Alejandra Araya y José Luis Martínez.

2 A lo largo de este trabajo, cada vez que se nombre a lo habitantes del Nuevo Mundo como indígenas será teniendo en cuenta que se trata de un tipo de sujeto creado en un contexto de dominación colonial (Martínez; Silverblatt). 
religión cristiana, el desarrollo de sistemas de escritura alfabética, etc. Sobre dichos ejes, jerarquizaciones, nociones y patrones de poder fue clasificada la población de América. Desde ahí se desplegó un proceso militar, político y religioso sustentado en una discursividad que buscaba legitimar la presencia del conquistador y su posesión sobre el otro.

Por medio de esta discursividad se clasificó, ordenó, sujetó y marginó a los sujetos indígenas y sus prácticas: religiosidad, saberes, sociabilidad, alimentación, sexualidad, etc., y se situaron cada una de ellas en el reino de la barbarie, la inmoralidad y la ilegalidad, que instalaron nuevas formas de estructurar el mundo y las subjetividades. En esta oportunidad me detengo a examinar cómo el discurso imperial marca, hiere y moldea el cuerpo de sus subordinados, lo cual posibilitó y justificó la sujeción y explotación de éste en la medida en que fue constituido como lo "no humano" o como una humanidad inferior ${ }^{3}$.

Señalar que el discurso imperial construye o moldea corporalidades específicas (unas que gobiernan y otras que se subordinan) implica entender al cuerpo como fenómeno social y cultural, materia simbólica, objeto de representaciones y de imaginarios, intermediario entre el yo y la sociedad. De esta manera el acercamiento al cuerpo que se propone en este trabajo se da a partir de concepciones culturales, que ponen el relieve en cómo los discursos y representaciones que se tejen en torno a éste forman parte de cierta trama y del sustento de sus expresiones ideológicas (Le Breton, La sociología; Porter).

3 En este sentido resulta interesante comparar la discusión que generó la cuestión indígena. Por un lado, tenemos a Ginés de Sepúlveda (Tratado de las justas causas de la guerra contra los indios), quien postulaba la inexistencia de humanidad en los indígenas; mientras que en el discurso de Bartolomé de las Casas (Brevísima relación de la destrucción de las Indias) el indígena aparece dotado de humanidad, pero una humanidad dócil idónea para la servidumbre, es decir, en ambos subyace la noción de inferioridad de lo indígena (Adorno, "La discusión"; Pagden, La caída). Por el otro, cabe señalar que el discurso imperial se preocupa también por moldear a los españoles que deben encarnar el proyecto de dominio. Esta cuestión quedará fuera de este estudio. 
A partir de estos planteamientos, me propongo analizar los discursos y representaciones desplegadas en torno a las enfermedades atribuidas a los indígenas circunscritos al Virreinato del Perú para el período 1570-1600, en las Relaciones Geográficas de Indias y algunos tratados médicos relevantes. Teniendo en cuenta que estas representaciones expresan algo más que una preocupación "científico-médica" o sanitaria, en la medida en que aludirín a un conjunto de ideas relacionadas con visiones sobre el ordenamiento simbólico, político y moral del espacio y de los sujetos coloniales.

Me centro en aquellas enfermedades de carácter contagioso (peste, lepra, sarna, apostemas, bubas, etc.) en relación con dos ejes. El primero de ellos guarda relación con el espacio, pues estas enfermedades estarín vinculadas con características de ciertos lugares del Nuevo Mundo. Según el corpus analizado, ellas se darían principalmente en ambientes húmedos y cálidos, lo cual dibujaría una especie de geografía del peligro. Es decir, el paisaje, a lo largo de este trabajo, se ha abordado como artefacto cultural, teniendo en cuenta los sistemas de ideas a través de los cuales es significado y se le otorga un sentido que va más allá de lo físico (Arnold; Nouzeilles).

Para el segundo eje, estas enfermedades se relacionan con conceptos como impureza, suciedad, abyección, contagio y peligro, los cuales son centrales a la hora de trazar fronteras simbólicas (Douglas; Kristeva; Le Breton, El sabor). Es decir, la enfermedad y sus cuidados emergerían dentro de los diversos discursos como dispositivos que pretenderían inculcar una visión degradada del otro (en cuanto el cuerpo es el reflejo del alma), que lo identifican con una condición abyecta y que llama al cuidado de los contactos, pues éstos convierten a los cuerpos en blanco de enfermedades y merman las cualidades físicas. Para dar cuenta de ello utilizo como corpus documental las relaciones geográficas relativas al Perú, recopiladas por Marcos Jiménez de la Espada, los tratados médicos confeccionados por Nicolás Monardes (1574), Juan de Cárdenas (1591) y Agustín Farfán (1595) y los principales vocabularios y diccionarios de la época.

Las relaciones geográficas corresponden a una serie de documentos elaborados, para los virreinatos de Nueva España y Perú, a través de 
cuestionarios expedidos por la Corona (Solano). Éstas pueden ser consideradas un programa de conocimientos sobre los territorios, espacios y sujetos que se estaban conquistando y construyendo. En esta oportunidad me detengo en el examen de las elaboradas para el Virreinato del Perú, estableciendo cómo ellas se articulan con el programa de dominio colonial desplegado en el continente americano.

Desde dicha perspectiva es posible explicar el porqué de la delimitación temporal de este trabajo, pues es en el periodo 1570-1600 cuando se concentran las más diversas prácticas (relaciones, crónicas, cartografía, etc., algunas de las cuales forman parte del desarrollo de este estudio) que confluyen en la búsqueda de una visión imperial sintética y universalista del Nuevo Mundo; proceso que concluye con la publicación de la obra Historia general de los hechos de los castellanos en las islas y Tierra Firme del mar Océano, del cronista Antonio de Herrera (Altuna; Cline).

Como lo señalé, las relaciones geográficas ofrecen información sobre las tierras americanas y sus habitantes: cabeceras principales, principales distancias, costumbres de los habitantes, principales enfermedades, entre otros ${ }^{4}$. De esta forma, tales relaciones, además de informar sobre las enfermedades, ofrecen cuantiosa información que me permitió establecer la relación entre éstas y los espacios, sujetos y comportamientos sociales.

Confronté estos documentos con los tratados médicos mencionados, con el objeto de identificar las estrategias de descripción, los adjetivos utilizados, los imaginarios políticos y sociales operantes a la hora de hacer referencia a las corporalidades, enfermedades y espacios indígenas. Además, el empleo de los diccionarios de autoridades y el Tesoro de la lengua castellana, de los años 1732 y 1539-1613, respectivamente, permite acceder a

4 Para tener un panorama de los aspectos tratados, se pueden revisar los cuestionarios que sirvieron para su confección, en la obra de Francisco Solano. 
los términos, en cuanto representaciones e imaginarios, implicados en las clasificaciones, tipologías y descripciones que se están elaborando.

Monardes, Cárdenas y Farfán fueron médicos que se preocuparon por asuntos médico-farmacológicos presentados con el descubrimiento del Nuevo Mundo. Sus textos fueron escritos y editados durante el siglo XVI y contaron con una amplia difusión más allá de América y Españas. Es necesario aclarar que a lo largo de este estudio estos textos serán considerados dentro de las prácticas que convergen en la consolidación de una visión imperial sintética y universalista de los territorios americanos. La expansión y conocimiento sobre el Nuevo Mundo significó también la expansión de los saberes médicos desarrollados en la metrópoli. Y con ello el despliegue de prácticas que significaron su naturaleza humana y sus padecimientos.

El saber y la práctica médica en España se caracterizaron, a lo largo del siglo XVI, por cerrarse a los nuevos saberes y prácticas que surgían en el escenario renacentista. No se sistematizaron los descubrimientos fisiológicos que comenzaron a dar forma a la llamada medicina moderna: una nueva patología, una visión organísmica o mecanicista del universo (de la que nacieron la iatromecánica y la iatroquímica) y una terapéutica que incorpora la química. Cuestiones que tensionaban y contradecían el galenismo hipocrático. Saber que se siguió practicando en suelo español (Abarracán; Barona; Porter y Vigarello).

El modelo humoral descrito en los textos hipocráticos (sigloV a.C.) y en la obra de Galeno (siglo II d. C.) se apoya en la imagen de las sustancias, sobre la de la apariencia y sobre la de los funcionamientos internos del cuerpo. Considera a la naturaleza humana el resultado de la combinación

5 Entre otras publicaciones con datos médico-farmacológicos sobre América, editadas durante el siglo XVI se destacan: Historia natural y moral de las Indias, escrita por Joseph de Acosta (Sevilla, 1590), y Opera Medicinalia, escrita por Francisco Bravo (México, 1570). Sobre esto ver la obra de Juan Comas et al. 
binaria de las cuatro cualidades elementales (caliente, frío, seco y húmedo), que originan los cuatro elementos (aire, fuego, tierra y agua), de cuya combinación surgen los cuatro humores (sangre, flema cólera y melancolía).

En este esquema, la salud es resultado del equilibrio humoral, mientras que la enfermedad se produce por la desajuste de éstos, por su desarmonía y alteración. Este funcionamiento anormal se podía explicar por llevar una vida desordenada, una mala alimentación, un medio o clima adverso, por trastornos propios del organismo o por la corrupción del agua o del aire. De esta manera, las afecciones se consideraban algo exclusivo de los individuos, pues existían entidades patológicas de por sí (Carmona 13-5; Porter y Vigarello 324-7). Tales cuestiones fueron retomadas por nuestros observadores a la hora de dar cuenta de las afecciones americanas.

El análisis del corpus está dado por su relación con las condiciones históricas y el contexto de ideas al cual se articulan. Si bien se reconoce que cada uno de los documentos utilizados posee especificidades según sus contextos de producción, en este trabajo se pone el relieve en los repertorios mentales vinculados con el cuerpo, la enfermedad y el contagio - con sus respectivas rupturas y continuidades - que emergen a la hora de dar cuenta sobre las relaciones e identificaciones coloniales. Sin obviar la heterogeneidad de estos discursos y representaciones, lo central son las formas como se definen las enfermedades, se narran y se juzgan, y cómo ello incide en el tejido de relaciones e identificaciones coloniales.

En este sentido, resultan centrales los conceptos de discurso y representación. Por discurso entiendo un conjunto de reglas y normas que se refiere a algo, prácticas sociales reguladas por juegos de poder (Foucault, El orden). Y por representación, las imágenes, palabras, gestos, etc. por medio de los cuales lo sujetos se perciben a sí mismos y a su exterior, las percepciones colectivas de un grupo en relación con su identidad o identidades; teniendo en cuenta que estas representaciones pueden ser reelaboradas subjetiva y colectivamente (Chartier). 


\section{Conocimientos y saberes en la construcción de los espacios y sujetos coloniales}

Dar cuenta de aquello sobre lo cual son posibles los conocimientos y saberes implica entender la episteme que allí opera, es decir, los códigos en que una cultura se funda "los que rigen su lenguaje, sus esquemas perceptivos, sus cambios, sus técnicas, sus valores, la jerarquía de sus prácticas”, fijando así "los órdenes empíricos con los cuales tendrá algo que ver y dentro de los que se reconocerá" (Foucault, Las palabras 5).

Desde esta perspectiva, referirse a la construcción de saberes en torno a los espacios y sujetos americanos no es un ejercicio exento de dificultades, pues implica, por una parte, reconocer un proceso de naturalización de las formas de conocer impuestas por la colonización, las cuales han instalado unas lecturas de América desde la inferioridad en relación con el referente europeo colonizador. Por la otra, y sin obviar el proceso de occidentalización mencionado, no debemos pasar por alto las tensiones, intersticios y porosidades que se producen a la hora de hablar sobre lo americano, lo cual genera diversas recepciones, debates y modificaciones a lo largo del tiempo en los diferentes contextos ${ }^{6}$.

6 En efecto, el simple acto de nombrar América ha sido un campo de disputa en los más variados contextos: desde el momento mismo de la expansión europea (Las Indias, Nuevo Mundo, etc.), pasando por el periodo de conformación y consolidación de los Estados Nacionales, hasta nuestro días, cuando sectores subalternos como los indígenas y afrodescendientes, o grupos comprometidos con ellos, han relevado nombres como Indoamérica y Afroamérica. ¿Qué imaginarios, opciones políticas, etc., laten en estos enunciados? Vemos como en el "simple" acto de nombrar se reafirman o resignifican las matrices sobre las cuales se ha entendido lo americano (O’Gorman, "Prólogo"; Rojo). Por otra parte, cabe destacar que la problematización en torno a los saberes, conocimientos y epistemes que operan al dar cuenta sobre lo americano fue uno de los ejes tratados en el Seminario Troncal I: "Problemas fundamentales de la cultura latinoamericana. Construyendo identidades y diferencias: América entre dos rupturas (siglos XVI-XVIII)", perteneciente al programa de Magíster en Estudios Culturales Latinoamericanos de la Universidad de Chile, coordinado por Alejandra Vega, Alejandra Araya y José Luis Martínez. 
La expansión europea sobre América significó la integración (subordinada) de ésta al sistema mundo y la apertura de la primera modernidad. Desde dicha expansión la modernidad se proveyó de elementos materiales y cognitivos. América no proporcionó sólo territorios, mano de obra y materias primas, sino también los elementos discursivos (articulados desde una episteme europea) para la construcción misma de la modernidad. Estos elementos discursivos se objetivaron en aparatajes disciplinarios y construcción de subjetividades. De esta manera se comenzó a articular una distinción frente a lo otro: la superioridad de unos sujetos (occidentales) y sus saberes respecto a otros (los indígenas), que instaló lo primitivo-irracional en tierras americanas y lo civilizado-racional en Europa ${ }^{7}$. Tal distinción se enmarca en las formas de conocer operantes en la sociedad europea: "la mentalidad europea no se preguntaba si la nueva humanidad se ubicaba fuera de los esquemas antropológicos escolásticos sino dónde se encontraba dentro de ellos" (Adorno, "El sujeto" 55).

Ese es el contexto epistemológico en el que se inscribe la proliferación de representaciones en torno a América. Describir equivale a desentrañar las analogías entre lo que se ve y lo que se sabe. Conocer y dar cuenta de la realidad forma parte de un proceso de reconocimiento de las coordenadas del imaginario europeo en un ámbito ajeno. Estas imágenes de la tradición europea serán utilizadas para proyectar el deseo: conocimiento y deseo se articulan en un ejercicio de comprensión y control de la realidad ajena.

Ahora bien, este esquema posee una contracara: el horror. Un cordón de horrores, encarnados en amazonas, gigantes, sodomitas, caníbales,

7 En este sentido, se ha postulado que la imagen del bárbaro y su deshumanización se establecieron como uno de los primeros métodos para conocer, clasificar y dar a conocer todo aquello con lo que los agentes colonizadores se encuentran y que les extraño culturalmente (Pagden, La caída). Por otra parte, cabe señalar que si bien es cierto que esta matriz eurocéntrica ha sido hegemónica a la hora de abordar a los sujetos, espacios, prácticas y saberes americanos, debemos tener en cuenta las apropiaciones y relecturas que se han hecho desde América. 
paganos, naturaleza monstruosa, etc. rodea a los objetos de deseo ${ }^{8}$. Estos horrores pueden traducirse como articulaciones simbólicas de la vivencia de la alteridad "lo monstruoso funciona en parte como interdicción, pero es representación simbólica de la alteridad” (Pastor, El jardín 75). Este otro emerge como una amenaza, articulado sobre el miedo a la destrucción simbólica de la subjetividad y la desintegración de los parámetros culturales:

... en ese contexto el deseo se define como auto-preservación y como control del otro, y la contigüidad que liga el objeto del deseo con el momento, la maravilla con el horror expresa simbólicamente la tensión entre exaltación del sujeto inseparable del logro del objeto del deseo entrevisto en la exploración y el terror a la destrucción del sujeto, a su aniquilación en el contacto con el otro. (Pastor, El jardin 78)

De ello se desprende que las imágenes y representaciones que traducen dicha experiencia secreten abyección por todas partes "pues la abyección es, en suma, el reverso de los códigos religiosos, morales, ideológicos, sobre los cuales se funda el reposo de los individuos y las treguas de las sociedades" (Kristeva 279). La abyección reviste formas específicas según los sistemas simbólicos y contextos sociohistóricos. En esta exposición el relieve está puesto en la construcción de sujetos y espacios abyectos en relación con la enfermedad, en cuanto sistema de descripción que sirve, entre otras cosas, para apropiarse y neutralizar estos espacios y sujetos, trazando las fronteras simbólicas mencionadas?.

En este acto de apropiación y neutralización de los espacios y sujetos, narrar se convirtió en una actividad central. De esta forma, relaciones geográficas, crónicas, tratados, etc. fueron máquinas de representación

8 De hecho, es posible rastrear en el interior de los diversos cuestionarios preguntas como "a qué parte están las amazonas” (1518), preguntas por las calidades y extrañezas en los cuestionarios de 1533 y 1534 y en 1556-1557 preguntas sobre los animales monstruosos (Olivera LXVI).

9 Otros trabajos se sitúan más bien en cómo la enfermedad, para el ámbito conventual, da cuenta de la construcción de subjetividades modernas, manifestadas en la individuación de los sujetos y la construcción de un yo (Araya, "Melancolía"). 
para describir e inventar lo americano (Nouzeilles 23). Aunque diferentes en estructura y contenido, estos textos dan cuenta de los procesos mentales mencionados. Así, estas obras trascienden el ámbito meramente documental, en cuanto fuente de información, para ser analizadas en el contexto de situación comunicativa en que se inscriben y en relación con su capacidad preformativa (Invernizzi; Mignolo).

\section{“Porque el calor y la humidad son las calidades mas dispuestas a engendrar corrupcion putrefacion é inmundicia”}

Dentro de los cuestionarios para la formación de las relaciones geográficas de Indias, ciertas preguntas relacionadas con las características del territorio ("Si es tierra llana, o áspera, rasa o montuosa") y el temple ("Y si es en tierra o puesto sano o enfermo") abrieron la posibilidad de enunciar la relación sujetos indígenas-espacios (Solano 81 y 83). Es decir, las respuestas que ellas encontraron establecieron que una tierra doblada y montuosa albergaba a indígenas poco domésticos o claramente no domesticados, o que en tierras cálidas y húmedas la población padecerá enfermedades contagiosas. Tales relaciones nos llevan al tema de la semejanza como principio constructivo de saber:

Dentro de la amplia sintaxis del mundo los diferentes seres se ajustan unos a otros; la planta se comunica con la bestia, la tierra con el mar, el hombre con todo lo que lo rodea. La semejanza impone vecindades que, a su vez, aseguran semejanzas. El lugar y la similitud se enmarañan; se ve musgo sobre las conchas, plantas en las cornamentas de los ciervos, especie de hierba sobre el rostro de los hombres. (Foucault, Las palabras 27)

De esta manera, el indígena se ajusta al espacio que lo rodea, y las relaciones entre sus características son bastante recurrentes, por ejemplo, la tierra viciosa se corresponde con indígenas viciosos. Así, los discursos sobre el mundo natural aparecen cargados de simbolismos que se refieren a cuestiones políticas, sociales y culturales (Martínez). 
Estas cuestiones ratifican la condición de natural de los indios, en cuanto vinculado y sometido a la tierra donde nació, la cual le confiere su temperamento y complexión (Bernard 113-4). Desde dicha perspectiva, los indígenas fueron identificados con un temperamento y complexión más débil. Tal como lo señala Juan de Cárdenas, la complexión de españoles sería colérica "la complesion mas alabada y aprobada por buena entre todas" (f. $18 \mathrm{v}$ ), pues otorga cualidades marcadas por el entendimiento y la templaza. De esta manera, el discurso sobre los humores posibilita ubicar la corporalidad española, sus disposiciones anímicas y temperamentales por sobre los demás habitantes de las tierras indianas. De hecho, los indígenas, según el mismo autor, se caracterizan por poseer una complexión flemática, la cual genera corporalidades débiles, perezosas y lentas en entendimiento. Cuestiones que se potenciaban en temples cálidos y húmedos ${ }^{10}$.

En las descripciones aquí analizadas se tiende a relacionar los temples cálidos y húmedos con excesos perjudiciales de todo tipo: naturaleza exuberante, enfermedades, vicios, pestilencia, etc. Por ejemplo, en la Relación de Santo Domingo de Chunchi se señala:

La tierra no es muy sana, por causa de que los llanos de Guayaquil y otros calientes están muy cerca, que de un cuarto de legua hasta los mesmos llanos, que habrá doce leguas, poco más o menos, todo es cálido; y destas partes, el invierno, con las aguas, se levantan muchas nieblas de los vapores de la tierra y suben a esta sierra; y como entonces los aires no tienen tanta fuerza que puedan trasponerlas de las sierras, se quedan en estas partes, y éstas causan humidad; demás de que la mesma constelación de la tierra es húmeda; $\mathrm{y}$ destas frialdades y neblinas proceden enfermedades. (Jiménez de la Espada 2: 286)

Al referirse a los habitantes de este temple, Juan López de Velasco, señala:

10 Para ver otros aspectos vinculados más bien con la topografía de los lugares y sus habitantes en el marco del discurso imperial, véase la obra de José Luis Martínez. 
... y aunque los naturales viven sanos, llegan pocos á muy larga vida, que en parte debe ser por el poco regalo y comodidad que tienen para la vida humana de comidas y camas y vestidos, y en parte por la desordenada y torpe bestialidad de vicios en que viven. (12)

¿En qué radica la homologación sujetos-espacios? ¿Qué imaginarios y tradiciones laten en dichas conexiones? El texto titulado Sobre los aires, aguas y lugares, de Hipócrates, trata sobre la importancia de conocer la posición, los tipos de aguas, las características del suelo y el temple de los diferentes lugares, para de esta manera conocer las características de sus habitantes, las enfermedades y peligros de los diferentes lugares.

A partir de dicho patrón de observación se establece que en los lugares con temple cálido y húmedo se encontrarían sujetos viciosos, enfermedades y peligros (aires pestilentes, pantanos, sabandijas, etc.), mientras que los lugares templados serían los más idóneos para el desarrollo y progreso humano (Hipócrates). Dicha distinción comenzó a operar a la hora de dar cuenta de esta otra naturaleza. López de Medel es bastante elocuente para dar cuenta sobre esta distinción, al referirse a los lugares más apropiados para habitar; excluye aquellos húmedos y calurosos, pues en "semejantes lugares mayores enfermedades hay que por acá y mayores aparejos para enfermar y morirse los hombres, por la particular destemplaza de aquellos lugares.... Entre tanto, los templados se caracterizan por no "haber exceso alguno y si le hay es muy poco [...] ser acomodadísima para la habitación de los hombres, por su grande templanza y maravillosa disposición para la salud humana” (133).

Por otro lado, es necesario anotar que en la documentación analizada son los indígenas quienes aparecen como los únicos habitantes de estas zonas; son ellos los que aparecen como débiles, sujetos a una tierra llena de vicios: "... aunque los de las tierras calientes, comprendidas entre los trópicos, son por lo ordinario de menor cuerpo, y más débiles y flacos por la relajación del calor y vicio de la tierra, que los criados en partes frías y fuera de los trópicos" (López de Medel 27).

De esta forma se entiende por qué las zonas cálidas y húmedas (habitadas principalmente por indígenas), en oposición a las templadas 
(las que prefieren ocupar los colonizadores), se caracterizan por sus excesos, que pueden ser extendidos al ámbito de lo social, y por su hostilidad para ser habitadas por los colonizadores. Las enfermedades vinculadas a conceptos de miseria y pestilencia, características de estos espacios, articulan ambas cuestiones ${ }^{11}$ :

... digo ques tierra enfermísima, porque ningund indio está con entera salud, porque todos a una estan llenos de lepra y miseria. Es tierra muy húmeda, porque de dia ni de noche deja de llover y de continuo está el pueblo tres leguas alrededor cubierto de niebla que jamás se quita sino es por maravilla. Son muy pocos los que tienen salud. (Jiménez de la Espada 2:244)

Señalar que la tierra es enferma se vincula con una naturaleza que da pie al padecimiento y a unos sujetos afectados por esa naturaleza; además, informa sobre el peligro de penetrar en esos espacios o mezclarse cultural o biológicamente con dichos sujetos. En cuanto a lo nocivo que podría llegar a ser el acto de ingresar a dichos espacios, la relación de la provincia de Jauja señala: "es el valle sano, y si algunas enfermedades tienen los indios, es de mudar de temple y por ir a las tierras calientes" (Jiménez de la Espada 1: 170). También, según Juan de Cárdenas, estas enfermedades se podían contagiar por imitar prácticas culinarias propias de los indígenas de estos espacios, como el comer carne cruda de especies como reptiles y gusanos.

Una de las relaciones recurrentes en la documentación es el temple húmedo-cálido y los males pestilenciales ${ }^{12}$. Según el Tesoro de la lengua castellana, pestilencia corresponde a: "lo mismo que peste", y peste, a "enfermedad contagiosa que comúnmente se engendra del aire corrompido" (f. 141). El aire corrompido era fruto de la humedad, pues ésta causaba la putrefacción del ambiente. Las aguas, la tierra y sus habitantes parecieran

11 Para ver otros aspectos vinculados con las características de estos espacios, véase la obra de David Arnold (125-135).

12 Véase, por ejemplo, "Relación que enbio a mandar su majestad se hiziese desta ciudad de Cuenca y de toda su provincia” (Jiménez de la Espada 2:266-7). 
estar impregnados de un olor que produce repugnancia. El olor aparece aquí como un indicador de peligro, rechazo, desigualdad y segregación; de esta manera es posible sostener que:

... existe un olor de la alteridad, una línea olfativa de demarcación entre lo de uno y lo de los demás [...] el olor es antropológicamente un marcador moral [...] lo que huele bien inspira confianza; lo que huele mal es tramposo y peligroso, $\mathrm{o}$ por lo menos aun desconocido y amenazador. (Le Breton, El sabor 236-7)

Así es como el olor a putrefacción se levanta como argumento que confirma el rechazo y situaciones de desigualdad, al tiempo que muestra la necesidad de mantener ello apartado, fuera de las relaciones sociales habituales. Es más, enfermedades contagiosas son asociadas con estos olores nauseabundos, amenazantes para quien los oliera; entonces, la distancia era obligatoria. Cabe recordar que la olfacción, hasta los aportes hechos por Louis Pasteur, desempeñó un rol muy importante en la definición de lo sano e insano (Delumeau 55).

Cabe aclarar que la impureza del aire y de las aguas, y junto con ello el desarrollo de las pestilencias, no era una cuestión que se remitiese sólo a los espacios geográficamente identificados como húmedos y cálidos. Algunos tratados médicos, como el Sevillana medicina, de Juan de Avión (siglo XIV), advierten sobre cómo la contaminación del aire de las aguas en los sectores más desposeídos propiciaba la incubación de enfermedades pestilenciales (Carmona 14). De esta manera es posible sostener que si bien la referencia a Hipócrates en las descripciones sobre los espacios enfermos americanos es clara, también es posible rastrear en ellas continuidades o resonancias con formas de nombrar, caracterizar y clasificar a los sujetos subalternos europeos.

Estas categorizaciones dan cuenta de un ejercicio por situar esta "nueva" naturaleza en un horizonte de comprensión europeo. Había que explicar de manera plausible la dominación sobre los nuevos dominios trasatlánticos y articular un arsenal de prácticas que permitieran establecer un orden colonial administrado desde la metrópoli. Mediante dicho ejercicio no sólo se construyó al otro americano, sino que se operó la construcción 
identitaria de los sujetos colonizadores europeos: sus espacios, sus prácticas y reafirmación sus lógicas de exclusión.

Este repertorio constituyó la experiencia sobre la cual se rearticularon, a la luz de la segunda modernidad bajo el paradigma de la diferencia (desde el siglo XVIII), las lecturas sobre lo americano como una región con un clima patológico, de poblaciones insalubres, corporal y mentalmente débiles, incompletas o deformes (Cañizares; Gerbi 3-31; Weinberg y Carrera). Esta cuestión encontró continuidad en el repertorio de prácticas que, durante el siglo XIX, dan forma y significan la tropicalidad, esto es, la forma occidental de definir algo ambientalmente distinto a lo visto en las zonas templadas. Aquí la enfermedad emergerá nuevamente como una forma de dar cuenta de la inferioridad, pero esta vez desde otras lógicas: desde las condiciones discursivas e institucionales de los imperialismos decimonónicos, que hacen hincapié en la diferencia y plantean de manera sistematizada el factor racial (Arnold; Caponi).

Tal como lo he señalado, la naturaleza no era algo separado de sus habitantes, entonces, ésta sólo podría albergar sujetos indígenas abyectos y peligrosos. Para afirmar ello considero necesario, por un lado, dar cuenta de los imaginarios y representaciones en torno a la figura del indígena durante el período en cuestión. Por el otro, cómo ellos se articulan con lo hasta aquí dicho sobre el espacio.

\section{Enfermedad, abyección y contagio: cuerpo físico como metáfora del cuerpo social}

Las caracterizaciones sobre la figura del indígena durante el siglo XVI se han estructurado desde la dominación. Esto quiere decir que - con diferentes énfasis - se enuncian en ellas la inferioridad del indígena respecto de la instalación de relaciones de poder asentadas en la desigualdad social (Pastor, Discurso 451-67). Estas caracterizaciones se manifestaron en diferentes aspectos, y uno de ellos fue el relieve puesto a los rasgos somáticos de los indígenas y a la somatización de sus prácticas. 
Canibalismo, sodomía y desnudez aparecen como los ingredientes infaltables en cualquier descripción sobre ellos (Amodio). Además, el cuerpo mismo es evidencia de ser otro, de allí que en algunas descripciones se recalquen las marcas y colores que impone la naturaleza: "Son los naturales y las gentes de aquel Nuevo Mundo de las Occidentales Indias de color bazo y como de un membrillo cocho los más morenos de ellos" (López de Medel 204). No obstante, dichas distinciones podían ser traspasadas y generar mezcla y confusión bastante; al respecto es el episodio narrado por Bernal Díaz, en el cual uno de los integrantes de la hueste de Cortés, después de haberse perdido y convivido con los indígenas, se rehúsa a volver con los suyos, ya que su cuerpo evidencia las marcas de la otredad: "que yo tengo labrada la cara e horadadas las orejas iqué dirían de mi desque me vean esos españoles ir desta manera?” (Díaz del Castillo 66).

Así, este cuerpo indígena y sus prácticas se presentan como el espejo donde el ideal de sujeto imperial moderno se contempla y produce la inversión de su propia imagen: razón y orden de los cuerpos contra irracionalidad y caos corporal. Esta imagen de pasiones desbordadas y seres confundidos con una naturaleza subhumana cobra fuerza a la hora de dar cuenta de las enfermedades y sus cuidados ${ }^{13}$.

Un tema no menor a la hora de abordar las enfermedades es la cuestión de la suciedad. Ella da pie, alberga o describe las enfermedades. Según Juan de Cárdenas, indígenas, negros, mulatos y mestizos, es decir, lo más bajo de la jerarquía social, eran los sujetos más sucios (ff. 196 r. y v.); es más, en una interesante analogía entre el cuerpo social y el cuerpo físico, este autor señala que las enfermedades "comiença por las partes mas suzias e inmundas del cuerpo humano” (f. 196 r.). Pero ¿qué rol cumple discursivamente la suciedad? Las sociedades europeas para esta época aún no

13 Cabe destacar en este punto que el cuerpo indígena no es el único que dentro de este programa de dominio imperial está siendo modelado. La Corona está tan preocupada de normar el cuerpo indígena como el del cristiano español, que roba mujeres e hijas y se amanceba, que juega naipes y bebe hasta embriagarse y perder los sentidos, que reniega de Dios, etc. 
poseían una sistematización de las prácticas de higiene, tal como hoy las conocemos. De esta forma, la limpieza guardaba relación con el orden y la moralidad, más que con una preocupación consciente por los agentes infecciosos que podrían acarrear alguna enfermedad.

Así es como suciedad, limpieza y enfermedad estarían cargadas de un contenido simbólico ligado a lo moral y a las jerarquías sociales. La suciedad estaría identificada con el bajo pueblo, los moros, los judíos, etc. (Vigarello). A la luz de ello, la suciedad debe ser vista como "el producto secundario de una sistemática ordenación y clasificación de la materia, en la medida en que el orden implica el rechazo de elementos inapropiados" (Douglas 54-5). En la suciedad se concentrarían los marginados de la sociedad europea. De esta manera, lo sucio remite a los límites y con lo que se desborda: escupo, leche, orina, excremento y sangre.

Desde dicha perspectiva se puede leer la mención, caracterización y comportamientos ante la enfermedad llamada cámaras. En efecto, las cámaras aparecen como una enfermedad común en los ambientes húmedos y cálidos, definidas como "el excremento del hombre, cuyo nombre se le debió dar porque siempre se exonera el vientre en lugar retirado y secreto"; o también como "el flujo de vientre, que ocasiona obrar repetidas veces en el tiempo, y por ello se usa en plural. Algunas veces suelen ser los cursos de sangre, por estar heridos los intestinos" (Real Academia).

Sangre y excremento, fluidos que corrompen el interior del cuerpo y amenazan con corromper el exterior. De hecho, enfermedades como sarna, apostemas, lepra y bubas se explicaban por la corrupción de la sangre: "La sarna se haze, quando ay mucha sangre o cuando se corrompe [...] cuando se haze de sangre demasiada, ó de sangre podrida y mucha, se conosce en el color del rostro colorado y encendido" (Farfán f. 315 v.). La corrupción se relaciona con el pudrimiento, pestilencia, contaminación, depravación de las buenas costumbres y carencia de pureza o virginidad (Covarrubias; Real Academia).

Sin embargo, la sangre no es el único factor que vendría a explicar el origen de las enfermedades. La lepra, la sarna, la peste, las apostemas y 
las bubas, en los tratados acá analizados, aparecen como enfermedades de orígenes pocos precisos: fluidos corporales, contacto sexual, acercamiento corporal e influencia del medio, lo cual, en palabras de Sontag, permite la adjetivación de las enfermedades y vincularlas con cuestiones morales y conservación del orden:

... cualquier enfermedad importante cuyos orígenes sean oscuros y sus tratamientos ineficaz [sic] tiende a hundirse en significados. En un principio se le asignan los horrores más hondos (la corrupción, la putrefacción, la polución, la anomia, la debilidad). La enfermedad misma se vuelve metáfora. Luego, en nombre de ella (es decir, usándola como metáfora) se atribuye ese horror a otras cosas, la enfermedad se adjetiva. (Sontag 61)

Es más, los métodos utilizados para su curación (purgas, sangrías y baños en determinados tipos de aguas) están ligados a acciones como limpiar, purificar y evacuar, lo cual nos remite a las nociones de limpieza y suciedad enunciadas más arriba:

Otro nacimiento de agua caliente hay a una legua e media desta ciudad; es muy caliente, nace en una quebrada de tierra caliente; báñanse algunas personas y haIlan remedio de algunas enfermedades, como son bubas, llagas viejas y sarna, porque sudan lo que quieren dentro de la misma agua. (Jiménez de la Espada 190)

Otro de los problemas asociados a estas enfermedades se vincula con los efectos somáticos que éstas presentan: la deformación de la piel por medio de las hinchazones, granos, heridas, etc. Por ello al referirse a los signos corporales de las bubas, Agustín Farfán señala:

Son tantos y tan diversos los accidentes de esta enfermedad, que a unos aflije con una manera de sarna y leprilla en algunas partes de su cuerpo, y a otros en todo el. A unos aflije con unos como empeynes y postillas en la cabeça y en el rostro, a otros aflije pelándoles las cejas y pestañas, la cabeça y la barba. (f. 83)

Acá el tema de la deformación del rostro resulta central, en la medida en que pone en tensión la definición de las identidades, elemento central para distinguir las oposiciones entre dominadores y dominados y mantener las jerarquías sociales. Tal como lo ha señalado Rolando Mellafe para el caso de las tapadas, en una sociedad que recién comenzaba a constituirse 
la no identificación de los rostros se tornaba una práctica peligrosa, en la medida en que implicaba la ocultación de la identidad (ya sea en términos de género, clase, edad, estado y naturaleza). De hecho, fue una práctica normada por las autoridades coloniales.

La piel traduce la diferencia individual, demarca el género, la condición social, la edad y la etnia. Es un límite, une, separa, organiza la relación con el mundo, encierra la individualidad, pero también es apertura, esto es, el punto de contacto con el mundo; por ello es conveniente que dicho encuentro se enmarque dentro de los parámetros establecidos. De ahí que el contacto de los cuerpos se haya erigido como una acción peligrosa (Le Bretón, El sabor 179-99). En este sentido puede ser leída la relación que se establece entre las altas tasas de mortalidad producidas por los "males pestilenciales" y el hacinamiento:

... y de enfermedades mueren de presente menos que entonces, porque les venían pestilencias y males contagiosos de virguelas, sarampión y otros géneros de enfermedades, que, viviendo en un galpón veinte o treinta moradores con sus mugeres y chusma, ninguno escapaba y por maravilla algunos. Entiendo que agora, aunque algunos males destos acuden, no son tan dañosos, por estar distintos y apartados cada casado en su casa en los pueblos fundados, y por los remedios que de los españoles y sacerdotes reciben consuelo grande que tienen. (Jiménez de la Espada 2:286)

Es interesante notar cómo el peligro en torno al contagio va totalmente ligado a la necesidad de imponer un orden determinado, es decir, más que terminar con el hacinamiento de los cuerpos por una preocupación sanitaria, lo que está en el centro es velar por un comportamiento basado en la moral cristiana, que se resume en la frase "cada casado en su casa”.

La amenaza de estos cuerpos se tornaba mayor en la medida en que eran capaces de traspasar las fronteras ambientales y transportar los males a lugares considerados sanos. Ejemplo de ello es la ciudad de San Francisco de Quito, que se caracterizaba por ser tierra sana; sin embargo, algunos de sus habitantes padecían del mal de bubas, enfermedad común en ambiente hostiles, debido a su contacto con las mujeres indígenas: 
"Las enfermedades más ordinarias son bubas, de las cuales participan algunos españoles poco recatados de la comunicación con mujeres naturales, las cuales de ordinario las heredan desde el vientre de sus madres" (Jiménez de la Espada 2: 206).

A partir de ello es posible afirmar que el contacto más peligroso era el contacto sexual. Éste fue un tema central a la hora de definir una de las enfermedades más peligrosas de la época, me refiero al mal de las bubas. Si bien es cierto que en algunos documentos éste aparece claramente identificado, en otros se le homologa a la lepra, a la peste, a la sarna, dado que sus síntomas eran similares:

Con esto [refiriéndose a las bubas] le pusieron varios y diversos nombres, llamándola unos lepra, otros lechenes, otros mentagra, otros mal muerto y otros elefancia, sin poder atinar ciertamente qué enfermedad era, porque ignoraban que fuese enfermedad nueva y queríanla reducir a algunas de las ya sabidas y escritas. (Monardes 46)

Teniendo en cuenta lo anterior, me atrevo a sostener que los significados e implicaciones en torno a las bubas pueden ser observados en otras enfermedades de carácter contagioso manifestadas en la epidermis. La principal característica de las bubas es que se trataba de un mal propiamente indiano, ello debido a que en América estarían las condiciones físicas idóneas para su desarrollo (calor y humedad); además, la inmundicia de los cuerpos indígenas actuaría como un catalizador en su incubación (Cárdenas ff. 196 r. y v.; Farfán; Monardes). Por otra parte, su contagio estaba dado por los actos sexuales "siempre se vienen a pegar de unos en otros, por la mayor parte por via de torpes suzios e inmundos actos" (Cárdenas f. 196). No obstante, dentro de la documentación el acto sexual que más atención o preocupación atrapa es aquel dado entre sujetos de diferentes naturalezas:

... las bubas tienen esta propiedad o amistad, de conservarse y hallarse siempre en sujetos suzios, llenos de inmundicia, por el qual respeto, vemos de ordinario, hallarse y començar este mal por negros, indios, mulatos, y gente que tiene mezcla de la tierra, porque todos estos, por la mayor parte biven con poca limpieza y recato, y por la misma razon veremos que siempre el dicho mal 
comiença $[. .$.$] pues como este mal tenga esta propiedad de proceder criarse$ y conservarse en semejantes sujetos, y partes del cuerpo, no es de maravillar, que por el consiguiente, ame para su misma conservacion tierras calientes y humidas, como son las indias, porque el calor y la humidad son las calidades mas dispuestas a engendrar corrupcion putrefacion é inmundicia. (Cárdenas ff. 196 r.y v.)

Como un español padeciese grandes dolores de bubas, que una india se las había pegado. (Monardes 43)

Los conquistadores debían presentarse como el orden y la moralidad, es decir, lo limpio y lo sano. En este sentido, los cuidados en torno a la enfermedad educan sobre los comportamientos sexuales idóneos para lo superior. Acá distingo dos perspectivas: una moralizante, que resalta el control sobre la lujuria, el dominio de la mente sobre el cuerpo, elemento distintivo de lo superior: el amo cristiano. Y otra que busca velar por el orden de las jerarquías, pues el sexo es la puerta de entrada a la mezcla racial y con ello, al caos y al peligro (Araya, "Un imaginario").

Aquí es donde el cuerpo físico se convierte en metáfora del cuerpo social. Se deben controlar las entradas y salidas. El cuerpo permeable es imperfecto, caótico y frágil; el impermeable, por el contrario, garantiza perfección, orden y continuidad. Así, el contagio de las enfermedades se constituyó en un elemento peligroso que amenazaba el equilibrio de la estructura social que se deseaba instaurar; por ende, era necesario encauzarlo. De esta forma, el peligro articulado en torno a la enfermedad posee un potencial que invita a articular el orden que se desea imponer ${ }^{14}$.

14 En este punto hago hincapié en la necesidad de dar cuenta de aquello sobre lo cual se estructuran los comportamientos ante el mestizaje, entendiendo cuáles son las formas de conocer que operan a la hora de clasificar, delimitar y normar este fenómeno en el contexto americano. Cuestión que se encuentra dentro de los objetivos del proyecto Fondecyt núm. 1080096: "Para un imaginario socio-político colonial (1650-1800)", del cual he sido invitada a participar de sus discusiones. Investigadora responsable Alejandra Araya. 
Este trabajo se inició con un conjunto de documentos que dan cuenta de saberes y prácticas sobre las enfermedades del siglo XVI. Éstos fueron leídos en relación con su contexto y reglas de producción, los intereses particulares y colectivos que se ponen en juego, los sujetos de enunciación y sus formas de circulación, y se comprendieron como artefactos que construyen, acompañan y autorizan la construcción de las relaciones coloniales y las marcas de lo colonial (colonialidad) operantes aún en nuestras sociedades $^{15}$. A partir de dicha lectura decidí hacer hincapié en cómo las prácticas en torno a las enfermedades dan cuenta de la construcción sujetos, subjetividades y relaciones coloniales.

Específicamente, este trabajo pretendió mostrar cómo durante el siglo XVI, en el Virreinato del Perú, dentro de ciertos esquemas constructivos de saber, se trazó una caracterización de los espacios y sujetos colonizados que los identificaba con una degradación peligrosa. Tal identidad se proyectaba desde un aparataje conceptual ya conocido por los sujetos colonizadores: enfermedad, vicios, excesos, suciedad, etc., donde confluyeron diferentes discursos que construyeron sujetos, espacios y prácticas en un esfuerzo por ordenar, controlar y neutralizar la alteridad e instalar un determinado orden social. Evidentemente existen continuidades en las formas de conocer, denominar, caracterizar y normar lo otro; sin embargo, resulta necesario preguntarse qué implica narrar el espacio americano desde esas matrices y cómo ello fue reafirmado, rearticulado o resignificado.

La sociedad que se gestaba en el espacio americano pretendía erigir un orden social basado en el respeto de cada uno de sus miembros a las jerarquías, roles, actitudes y deberes establecidos (Bernard y Gruzinski 335-51).

15 Considero pertinente mencionar el trabajo de Jorge Cañizares, pues en éste se muestra que nuestras "sensibilidades historiográficas modernas y posmodernas" se originaron en el siglo XVIII a la luz de las disputas epistemológicas sobre cómo escribir la historia del Nuevo Mundo. 
De tal manera, las prácticas aquí analizadas pueden leerse como dispositivos de los procesos colonizadores capaces de caracterizar y construir tipos de sujetos, distribuyéndolos en espacios y jerarquías sociales precisas. Ante ello se debe contraponer la posibilidad de apropiación, negociación o recreación que estos sujetos realizaron de dichas prácticas para construirse a lo largo del tiempo en los distintos espacios y contextos (cuestión no elaborada en esta comunicación).

A lo largo del análisis pude apreciar que lo abyecto cobró relevancia a la hora de proteger las fronteras de la subjetividad y de los parámetros culturales. Lo abyecto permite identificar a los indígenas con el peligro y dibujar límites que afirman o reconfiguran las relaciones de poder, prácticas de dominación y categorías identitarias; sin embargo, el peligro articulado en torno al caos también es poder, es decir, posee un potencial que invita a articular el orden que se desea imponer (Douglas 83-101). De este modo, la constante enunciación de lo abyecto permite justificar y llevar a cabo la intervención europea como la necesaria interacción de la diferencia fundamental entre conquistador y colonizado.

\section{Bibliografía}

\section{FUENTES PRIMARIAS}

Cárdenas, Juan de. Problemas y secretos maravillosos de las Indias. 1591. Madrid: Cultura Hispánica, 1945. Impreso.

Covarrubias Orozco, Sebastián de. Tesoro de la lengua castellana o española. Madrid, 1611. Impreso.

Díaz del Castillo, Bernal. Historia verdadera de la conquista de la Nueva España. México: Porrúa, 1970. Impreso.

Farfán, Agustín. Tractado breve de medicina. Colección Incunables Americanos 10. 1595. Madrid: Cultura Hispánica, 1944. Impreso.

Jiménez de la Espada, Marcos, ed. Relaciones geográficas de Indias-Perú. 3 vols. Madrid: BAE, 1965. Impreso. 
López de Medel, Tomás. De los tres elementos: tratado sobre la naturaleza y el hombre del Nuevo Mundo. 1570. Madrid: Alianza, 1990. Impreso.

López de Velasco, Juan. Geografía y descripción universal de las Indias. Madrid: Fortanet, 1984. Impreso.

Monardes, Nicolás. Herbolaria de Indias. México: Instituto Mexicano del Seguro Social, 1990. Impreso.

Solano, Francisco. Cuestionarios para la formación de las relaciones geográficas de Indias, siglos XVI-XIX. Madrid: CSIC, 1988. Impreso.

\section{FUENTES SECUNDARIAS}

Abarracan, Agustín. “La medicina española de los siglos XVI, XVII y XVIII y su influencia en Colombia”. Cuadernos Hispanoamericanos, 472 (octubre 1989): 31- 43. Impreso.

Adorno, Rolena. "El sujeto colonial y la construcción cultural de la alteridad". Revista Crítica Literaria Latinoamericana, 14.28 (1988): 55-56. Impreso.

---. "La discusión sobre la naturaleza del indio". América Latina: palabra, literatura e cultura. Comp. Ana Pizarro. São Paulo: Memorial, 1993. Impreso.

Altuna, Elena. El discurso colonialista de los caminantes, siglos XVII-XVIII. Ann Arbor: Centro de Estudios Literarios Antonio Cornejo Polar, 2002. Impreso.

Amodio, Emanuele. Formas de alteridad: construcción y difusión de la imagen del indio americano a Europa durante el primer siglo de la conquista de América. Quito: AbyaYala, 1993. Impreso.

Araya, Alejandra. "Melancolía, hipocondría e histeria o las enfermedades del individuo moderno: una mirada desde la historia de las mentalidades y la historia del cuerpo". Psiquiatría y Salud Mental, 22.3-4 (2005): 205-218. Impreso.

--.. "Un imaginario para la mezcla: mujeres, cuerpo y sociedad colonial". Mujeres chilenas, fragmentos de una historia. Comp. Sonia Montencino Aguirre. Santiago de Chile: Catalonia, 2008. 31-40. Impreso.

Arnold, David. La naturaleza como problema histórico. México: FCE, 2000. Impreso.

Barona, Joseph Luis. Sobre medicina y filosofía natural en el Renacimiento. Godella, España: Seminari d'Estudis sobre la Ciència, 1993. Impreso.

Bernand, Carmen. "Mestizos, mulatos y ladinos en Hispanoamérica: un enfoque antropológico de un proceso histórico". Motivos de la antropología americanista. Indagaciones en la diferencia. Coord. Miguel León-Portilla. México: FCE, 2001. Impreso. 
Bernand, Carmen y Serge Gruzinski. Del descubrimiento a la conquista: la experiencia europea, 1492-1550. T. 1 de Historia del Nuevo Mundo. México: FCE, 1999. 335- 351. Impreso.

Bourdieu, Pierre. La dominación masculina. Barcelona: Anagrama, 2000. Impreso.

Cañizares, Jorge. Cómo escribir la historia del Nuevo Mundo. México: FCE, 2007. Impreso.

Carmona, Juan. Enfermedad y sociedad en los primeros tiempos modernos. Sevilla: Universidad de Sevilla, 2005. Impreso.

Caponi, Sandra. "Coordenadas epistemológicas de la medicina tropical". História, Ciências, Saúde-Manguinhos, 10.1 (2003): 113-49. Web. Jul. 2009

Chartier, Roger. El mundo como representación. Barcelona: Gedisa, 2002. Impreso.

Cline, Howard. "The Relaciones Geográficas of the Spanish Indies, 1577-1648”. Handbook of Middle American Indians. Vol. 12. Ed. Robert Wauchope. Dallas: University of Texas Press, 1972. Impreso.

Comas, Juan, José Luis Fresquet Febrer, José María López Piñero. El mestizaje cultural y la medicina novohispana del siglo XVI. Valencia: Instituto de Estudios Documentales e Históricos sobre la Ciencia, 1995. Google Books. Web. Jul. 2009.

Delumeau, Jean. El miedo en Occidente. Madrid: Taurus, 1989. Impreso.

Douglas, Mary. Pureza y peligro. Madrid: Siglo XXI, 1973. Impreso.

Foucault, Michel. El orden del discurso. Barcelona: Tusquets, 1980. Impreso.

---. Las palabras y las cosas. Madrid: Siglo XXI, 1999. Impreso.

Gerbi, Antonello. La disputa del Nuevo Mundo: historia de una polémica 1750-1900. México: FCE, 1993. Impreso.

Gruzinski, Serge. La colonización de lo imaginario: sociedades indígenas y occidentalización en el México español. Siglos XVI-XVII. México: FCE, 1991. Impreso.

Invernizzi, Lucía. "La representación de la tierra de Chile en cinco textos de los siglos XVI y XVII". Revista Chilena de Literatura, 23 (1984): 5-37. Impreso.

Hipócrates. "Sobre los aires, aguas y lugares". Tratados Hipocráticos. Vol. 2. Madrid: Gredos, 1983. 39-88. Impreso.

Kristeva, Julia. Los poderes de la perversión. Madrid: Siglo XXI, 2006. Impreso.

Le Breton, David. El sabor del mundo: una antropología de los sentidos. Buenos Aires: Nueva Visión, 2007. Impreso.

---. La sociología del cuerpo. Buenos Aires: Nueva Visión, 2002. Impreso. 
Martínez, José Luis. “Construyendo mundos: el 'nacimiento’ de los indios en los Andes del siglo XVI". Del Viejo al Nuevo Mundo: mentalidades y representaciones desde América. Coords. Alejandra Araya, Azún Candina y Celia Cussen. Santiago: Universidad de Chile, 2008. Impreso.

Mignolo, Walter. "El mandato y la ofrenda: la descripción de la ciudad y provincia de Tlaxcala, de Diego Muñoz de Camargo, y las Relaciones de Indias". Nueva Revista de Filología Hispánica, 35.2 (1987): 451-84. Impreso.

Maffesoli, Michel. La lógica de la dominación. Barcelona: Península, 1997. Impreso.

Martínez, José Luis. “Textos y palabras: cuatro documentos del siglo XVI”. Revista de Estudios Atacameños, 10 (1992): 133-47. Impreso.

Mellafe, Rolando. "Las tapadas y los tapados". La memoria de América colonial. Eds. Rolando Mellafe y Lorena Loyola Goich. Santiago: Editorial Universitaria, 1994. Impreso.

Nouzeilles, Gabriela, comp. La naturaleza en disputa: retóricas del cuerpo y el paisaje en América Latina. Buenos Aires: Paidós, 2002. Impreso.

O’Gorman, Edmundo. La invención de América. México: FCE, 1986. Impreso.

Pagden, Anthony. La caida del hombre natural. Madrid: Alianza, 1988. Impreso.

---. Señores de todo el mundo: ideologías del imperio en España, Inglaterray Francia (en los siglos XVI, XVII y XVIII). Madrid: Península, 1997. Impreso.

Pastor, Beatriz. Discurso narrativo de la conquista de América. La Habana: Casa de las Américas, 1983. Impreso.

---. El jardín y el peregrino. México: UNAM, 1999. Impreso.

Porter, Roy. "Historia del cuerpo". Formas de hacer historia. Ed. Peter Burke. Madrid: Alianza Universidad, 1993. 255-86. Impreso.

Porter, Roy y Georges Vigarello. "Cuerpo, salud y enfermedades". Historia del cuerpo. Eds. Alain Corbin, Jean Jacques Courtine y Georges Vigarello. España: Taurus, 2004. 323-57. Impreso.

Rojo, Grinor. “Nota sobre los nombres de América”. Atenea, 483 (2001): 63-76. Impreso.

Real Academia Española. Diccionario de la lengua española. Web. Nov. 2008.

Silverblatt, Irene. "El surgimiento de la indianidad en los Andes del Perú central: el nativismo del siglo XVII y los muchos significados de "indio". La formación del otro. Vol. 3 de De palabra y obra en el Nuevo Mundo. Coords. Gary Gossen, Jorge Klor de Alva, Manuel Gutiérrez y Miguel León-Portilla. Madrid: Siglo XXI, 1992.459-82. Impreso. 
Sontag, Susan. La enfermedad y sus metáforas. Madrid: Taurus, 1996. Impreso.

Vigarello, Georges. Lo limpio y lo sucio: la higiene del cuerpo desde la Edad Media. Madrid: Alianza, 1991. Impreso.

Weinberg, Gregorio y Germán Carrera Damas. "Sobre la significación histórica de América Latina”. Historia general de América Latina. Ed. Estevao de Rezense Martins. Madrid: Trotta, 2006. Impreso.

Fecha de recepción: 4 de marzo de 2008.

Fecha de aprobación: 6 de julio de 2009. 